\title{
Prognostic Impact of Array-based Genomic Profiles in Esophageal Squamous Cell Cancer
}

\author{
Ana Carneiro*1,2, Anna Isinger ${ }^{1}$, Anna Karlsson ${ }^{1}$, Jan Johansson ${ }^{3}$, \\ Göran Jönsson ${ }^{1}$, Pär-Ola Bendahl ${ }^{1}$, Dan Falkenback ${ }^{4}$, Britta Halvarsson ${ }^{5}$ and \\ Mef Nilbert ${ }^{1,6}$
}

Address: ${ }^{1}$ Department of Oncology, Lund University Hospital, 22185 Lund, Sweden, ${ }^{2}$ Department of Clinical Oncology, Portuguese Institute of Oncology, 1099-023 Lisbon, Portugal, ${ }^{3}$ Department of Surgery, University Hospital, 22185 Lund, Sweden, ${ }^{4}$ Department of Surgery, Helsingborg Hospital, 25187 Helsingborg, Sweden, ${ }^{5}$ Department of Pathology, Helsingborg Hospital, 25187 Helsingborg, Sweden and ${ }^{6}$ Department of Clinical Sciences, Copenhagen University and Clinical Research Unit, Hvidovre Hospital, 2650 Hvidovre, Denmark

Email: Ana Carneiro* - Ana.Carneiro@med.lu.se; Anna Isinger - Anna.Isinger@med.lu.se; Anna Karlsson - Anna_F.Karlsson@med.lu.se; Jan Johansson - Jan.Johansson@med.lu.se; Göran Jönsson - Goran_B.Jonsson@med.lu.se; Pär-Ola Bendahl - Par-Ola.Bendahl@med.lu.se; Dan Falkenback - Dan.Falkenback@med.lu.se; Britta Halvarsson - Britta.Halvarsson@med.lu.se; Mef Nilbert - Mef.Nilbert@med.lu.se

* Corresponding author

Published: II April 2008

BMC Cancer 2008, 8:98 doi:10.1/86/147|-2407-8-98
Received: 19 October 2007

Accepted: II April 2008

This article is available from: http://www.biomedcentral.com/147/-2407/8/98

(c) 2008 Carneiro et al; licensee BioMed Central Ltd.

This is an Open Access article distributed under the terms of the Creative Commons Attribution License (http://creativecommons.org/licenses/by/2.0), which permits unrestricted use, distribution, and reproduction in any medium, provided the original work is properly cited.

\begin{abstract}
Background: Esophageal squamous cell carcinoma (ESCC) is a genetically complex tumor type and a major cause of cancer related mortality. Although distinct genetic alterations have been linked to ESCC development and prognosis, the genetic alterations have not gained clinical applicability. We applied array-based comparative genomic hybridization $(\mathrm{aCGH})$ to obtain a whole genome copy number profile relevant for identifying deranged pathways and clinically applicable markers.
\end{abstract}

Methods: A $32 \mathrm{k} \mathrm{aCGH}$ platform was used for high resolution mapping of copy number changes in 30 stage I-IV ESCC. Potential interdependent alterations and deranged pathways were identified and copy number changes were correlated to stage, differentiation and survival.

Results: Copy number alterations affected median $19 \%$ of the genome and included recurrent gains of chromosome regions 5p, 7p, 7q, 8q, 10q, 11q, 12p, 14q, 16p, 17p, 19p, 19q, and 20q and losses of 3p, 5q, 8p, 9p and IIq. High-level amplifications were observed in 30 regions and recurrently involved 7p I I (EGFR), I I I 3 (MYEOV, CCND I, FGF4, FGF3, PPFIA, FAD, TMEM I 6A, CTTS and SHANK2) and I I 22 (PDFG). Gain of 7p22.3 predicted nodal metastases and gains of Ip36.32 and $19 \mathrm{pl} 3.3$ independently predicted poor survival in multivariate analysis.

Conclusion: aCGH profiling verified genetic complexity in ESCC and herein identified imbalances of multiple central tumorigenic pathways. Distinct gains correlate with clinicopathological variables and independently predict survival, suggesting clinical applicability of genomic profiling in ESCC.

\section{Background}

Esophageal squamous cell carcinoma (ESCC) is a major cause of cancer-related mortality worldwide. Despite advances in diagnostic methods and combined treatment modalities, the majority of the tumors are diagnosed at advanced stages and the overall 5-year survival rate 
remains 40\%. ESCC develops through a multistep process from dysplasia, through carcinoma in situ to invasive carcinoma, and the acquisition of genetic alterations is tightly related to the dysplasia-carcinoma sequence [1]. The characterization of genetic alterations inherently linked to ESCC development and an in-depth understanding of the molecular mechanisms underlying carcinogenesis and growth control may therefore provide information relevant for early tumor detection, refined prognosis and development of novel targeted therapeutics.

Loss of heterozygozity (LOH) studies and conventional comparative genomic hybridization (CGH) analyses have demonstrated genetic complexity in ESCC and have identified multiple recurrent copy number alterations, namely gains of 3q, 5p, 7q, 8q, 11q, 12p, 20p and 20q [2-6]. Amplifications of regions harbouring oncogenes e.g. $7 \mathrm{p} 12$ (EGFR), 8q24 (MYC), 17q21 (FGFR) and 11q13 (e.g. CCND1, FGF4/3, and EMS1) have consistently been observed [7-12]. Losses, albeit at a lower frequency than gains, have recurrently involved $3 p, 5 q, 9 p, 13 q, 18 q$ and $21 \mathrm{q}$ and include target genes such as FHIT, APC, RB1 and CDKN2A [3,13-16]. Moreover, some of the changes identified, e.g. gain of 8q24,11q13, 12p, and 20q12 and loss of $3 p$ have been associated with poor prognosis, but genetic alterations and biological characteristics have so far had a limited impact on clinical prognostication and treatment. Taken together, these findings suggest that genetic profiling can be a useful diagnostic tool in ESCC, whereas its prognostic role remains uncertain. We used array-based CGH (aCGH) for high resolution mapping in 30 ESCC and demonstrate that copy number changes detected by aCGH provide prognostic information beyond that of classical clinicopathological variables.

\section{Methods}

\section{Tumor tissue}

All 30 patients, 24 men and 6 women with a mean age of 64 (range 54-78) years, were recruited from the southern Sweden health care region and had undergone primary esophagectomy at the Department of Surgery, Lund University Hospital. None of the patients had received neoadjuvant radiotherapy or chemotherapy. Tumor tissue collected at surgery was stored at $-80^{\circ} \mathrm{C}$ until DNA extraction. Stage (according to the International Union Against Cancer) was I in 3 cases, II in 9, III in 7, and IV in 11 cases (see Additional file 1). Presence of $=50 \%$ tumor cells in the tissue was verified by touch imprints, which were stained with Hematoxilin-Eosin and evaluated by a gastrointestinal pathologist (B.H.). All deaths were ESCC related, the median follow up was 21 (range 1-46) months for the survivors. Written informed consent was provided by all patients and the study was approved by the Lund University ethics committee.

\section{BAC Array Platform}

We used the $32 \mathrm{k}$ human genome high-resolution BAC rearrayed clone set, Version 1.0 from the BACPAC Resource Center at Children's Hospital Oakland Research Institute, Oakland (CA, US), produced at the Swegene DNA Microarray Resource Center (GEO platform repository accession GPL4723) [17], Department of Oncology, Lund University with a resolution $>80 \mathrm{~kb}$.

\section{DNA isolation, labelling and hybridization}

DNA was extracted, labelled and hybridized as previously described [17]. A commercial obtained DNA, derived from a pool of normal human males (Promega, Madison, WI, USA) was used as reference. Scanning was performed using an Agilent microarray scanner (Agilent Technologies, Palo Alto, CA, USA).

\section{Image processing and data analysis}

Scanned arrays were analyzed using Gene Pix Pro 4.1 (Axon Instruments, MDS Analytical Technologies, Ontario, Canada) and bad spots were "flagged" during manual inspection. The quantified data matrix was loaded into Bio Array Software Environment (BASE)[18] and filtering and normalization were performed herein [19]. Correction of background intensities of Cy3 and Cy5 were calculated using median-feature and median-local background intensities of the uploaded file. Intensity ratios were calculated from the background tumor channel (ch1) divided with the reference channel (ch2). Spots flagged as bad were filtered out from further analysis and were regarded as missing values. A signal to noise ratio $(\mathrm{SNR})=5$ was set for both channels. Data were normalized using an implementation of a pin-based Lowess algorithm [20] in BASE excluding the X chromosome. A moving average smoothing algorithm with a $200 \mathrm{kbp}$ sliding window was used and a BASE-adapted CGH-plotter software was used to identify regions of gains and losses excluding the $\mathrm{X}$ and the $\mathrm{Y}$ chromosomes [21]. A region of gain or loss was defined as two or more consecutive clones showing an absolute $\log _{2}$ ratio $\geq 0.2$ and high-level amplifications as a $\log _{2}$ ratio $\geq 1.5$.

\section{Statistical Analysis}

A Chi2 test was used to identify differences between copy number changes and clinicopathological characteristics. For survival analysis, the Kaplan Meier method was used to estimate relevant event variables, and the log-rank test was used to compare survival between two strata. The Cox proportional hazards model was used for univariate and multivariate survival analyses. Cox analysis was first used for all clones, thereafter two or more consecutive significant $(P<0.05)$ clones (interrupted only by one or two clones) were re-analysed as regions affected by gains and losses. Regions significantly $(P<0.05)$ linked to stage/ outcome in univariate analysis were included in the mul- 
tivariate analysis. All covariates were evaluated for adherence to the assumption of proportional hazards by calculating Schoenfeld residuals. Correlations between changes within a same pathway were analysed using pairwise correlation. CGH profiles were classified as gains or losses according to the dominating variable in the region corresponding to the gene locus. After Bonferroni correction correlations with $P<0.05$ were considered significant. Stata 9.2 (StataCorp LP, College Station, TX 77845, USA) was used for the statistical calculations.

\section{Immunohistochemical Staining}

Serial $4-\mu \mathrm{m}$ sections from one representative paraffinembedded tumor block were used for immunostaining using a monoclonal antibody against human EGFR at a dilution of 1:50 (DAKO, Glostrup, Denmark). The slides were evaluated as no staining; $1+$ (cytoplasmic staining or discontinuous membrane staining); $2+$ (membrane staining with moderate intensity), and 3+ (intense staining with retained membranous staining). Interpretation of the staining was performed by two of the authors (AC and $\mathrm{MN}$ ), who were blinded to the copy number changes and the clinical data.

\section{Results}

The median number of losses per tumor was $6.9 \%$ clones (range $0.1-24 \%$ ) and the median number of gained clones was $9.8 \%$ (range 1.1-21\%). Recurrent gains identified in at least $60 \%$ of the tumors involved chromosome regions $5 \mathrm{p}, 7 \mathrm{p}, 7 \mathrm{q}, 8 \mathrm{q}, 10 \mathrm{q}, 11 \mathrm{q}, 12 \mathrm{p}, 14 \mathrm{q}, 16 \mathrm{p}, 17 \mathrm{p}, 19 \mathrm{p}$, $19 \mathrm{q}$, and 20q. Likely target genes include TERT, EGFR, MYC, MYEOV, CCND1, FGF4, FGF3, CTTN and AKT1. Loss of genetic material in at least $40 \%$ of the samples affected 3p, 5q, 8p, 9p and 11q (Table 1). A homozygous deletion of $9 \mathrm{p} 21.3$, corresponding to the CDKN2A locus, was identified in one case and was verified with PCR using CDKN2A-specific primers (sequences available from the authors upon request, data not shown). High-level amplifications were observed in 33 regions and recurrently involved 11q22 (harbouring PDFG in 3 tumors), 11q13 (in 11 tumors, encompassing MYEOV, CCND1, FGF4, FGF3, PPFIA, FAD, TMEM16A, CTTS and SHANK2) and 7p11 (including EGFR in 4 tumors). Overexpression of EGFR was validated by immunohistochemistry, which revaled a highly positive $(3+)$ staining in 19 tumors, 12 of which had copy number gain of $7 \mathrm{p} 11$. All 4 tumors with HLA of the EGFR locus showed 2+ or 3+ EGFR staining.

Table I: Summary of the most frequent copy number gains and losses. Table listing the most frequent copy number gains and losses, sorted in decreasing order, in relation to tumor stage. Columns give the cytoband, start reporter, end reporter, size (Mbp), and candidate genes in the region.

\begin{tabular}{|c|c|c|c|c|}
\hline Cytoband & Start reporter & End reporter & Size (Mbp) & Candidate genes \\
\hline \multicolumn{5}{|l|}{ Gains ( $\geq 60 \%$ ) } \\
\hline $5 p / 5.33$ & RPII-8IIII 5 & CTD-2296H22 & 1.8 & TERT \\
\hline $7 \mathrm{p} 22.3$ & CTD-2245C5 & RPII-745MI8 & 2.3 & MADILI, NUDTI \\
\hline $7 p \mid 1.2$ & RPII-449G3 & RPII-535NI2 & 1.1 & \\
\hline $8 q 24.13-q 24.23$ & RPII-I50NI3 & RPII-|4IJ23 & 10.5 & MYC, WISPI \\
\hline $8 q 24.3$ & CTD-2330CI5 & CTD-2300118 & 1.5 & FOXHI \\
\hline $10 q 26.3$ & RPI3-I37AI7 & RPII-I065FI6 & 0.8 & \\
\hline I IqI3.3-I IqI3.4 & RPII-433AI 8 & RPII-574F24 & 1.8 & \\
\hline $12 p \mid 3.33$ & CTD-2094CI4 & RPII-574G8 & 0.2 & \\
\hline $14 q 32.33$ & CTD-2344PI 2 & RPII-603LI & 0.4 & $A K T I$ \\
\hline $16 p \mid 3.3$ & RPII-344L6 & RPII-680M24 & 3.2 & \\
\hline $17 p|3|$. & RPII-205DI7 & RPII-63C7 & 0.6 & \\
\hline $19 p \mid 3.3$ & RPII-5I9F9 & RPII-8IM8 & 1.6 & \\
\hline $19 q 13.42$ & CTD-2503B7 & RPII-528E9 & 0.3 & \\
\hline $20 q 13.33$ & CTD-2022NII & RPII-350GI5 & 2.4 & \\
\hline \multicolumn{5}{|l|}{ Losses ( $\geq \mathbf{4 0} \%)$} \\
\hline 3p26.3-p24.2 & RPII-359E9 & RPII-5I2OI8 & 3.5 & RARB, TOP2B \\
\hline $3 p|4.2-p| 4.1$ & RPII-350E2I & RPII-I75F9 & 6.9 & FHIT \\
\hline $3 p|4.1-p| 3$ & RPII-607B7 & RPII-744B4 & 5.8 & \\
\hline $5 q|2.3-q| 3.1$ & RPII-I58G8 & RPII-633F2 & 0.9 & PIK3RI \\
\hline $8 \mathrm{p} 23.2$ & RPII-46MI5 & RPII-593J22 & 2.2 & \\
\hline $9 \mathrm{p} 24.3-\mathrm{p} 24.2$ & RPII-272N I6 & RPII-778P24 & 3.1 & MTAP, CDKN2A, CDKN2B \\
\hline $9 \mathrm{p} 23$ & RPII-6HI8 & RPII-3|2GI & 1.9 & \\
\hline $9 p 21.3$ & RPII-II3DI9 & RPII-I6PI2 & 5.2 & \\
\hline $1 / q 25$ & RPII-2I7L2I & CTD-2270LI7 & 2.4 & ATM \\
\hline
\end{tabular}


To evaluate whether genes from a same signaling pathway were correlated, a complementary analysis of pairs of genomic loci harboring genes (CDKN2A, MDM2, RB, MDM4, CDKN1A, PIK3CA, PTEN, AKT1, TP53, MYC, CCND1, CCNE1, BCL2, CDK4, E2F3) from central tumorigenic pathways was performed. Significant correlations $(P<0.05)$ were identified between gain of the MDM4 locus and loss of the RB locus, gain of $M D M 2$ and gain of TP53, gain of BCL2 and loss of CDKN1A, gain of BCL2 and loss of CDKN2A, gain of CCND1 and loss of $C D K N 2 A$. Significant negative correlations were found between gain of MDM2 and gain of PIK3CA, gain of PIK3CA and loss of E2F3, loss of PTEN and gain AKT1, and concordant gain of $A K T 1$ and gain of CDK4. Pairwise correlation analysis between members of the EGFR pathway identified significant $(P<0.05)$ correlations between gains of AKT1/HER3, MAPK1/PIK3CA, and MAPK1/AKT1 and between gain of EGFR and loss of PTEN.

Despite genetic complexity (Figure 1), the genomic profiles were found to correlate with tumor stage, differentiation, and development of metastases with a lower (mean $13 \%$ versus $25 \%$ ) number of changes in highly differentiated ESCC than in poorly differentiated tumors (see Additional file 2). A Chi2 test identified $\sim 400$ clones that mapped to 6 genomic regions (2p11.1-2q11.2, 2q35, $3 \mathrm{p} 21.31,4 \mathrm{q} 12,4 \mathrm{q} 21.3-4 \mathrm{q} 28.3,5 \mathrm{q} 12.1)$ that were significantly $(\mathrm{P}<0.05)$ more often found in poorly differentiated tumors. The chromosomal regions most frequently affected by copy number gains differed between stage I and stage II-IV tumors. Gains of 6p25.3, 12p13.33 and 17 p13.1 were present in all stage I tumors. Stage II-IV
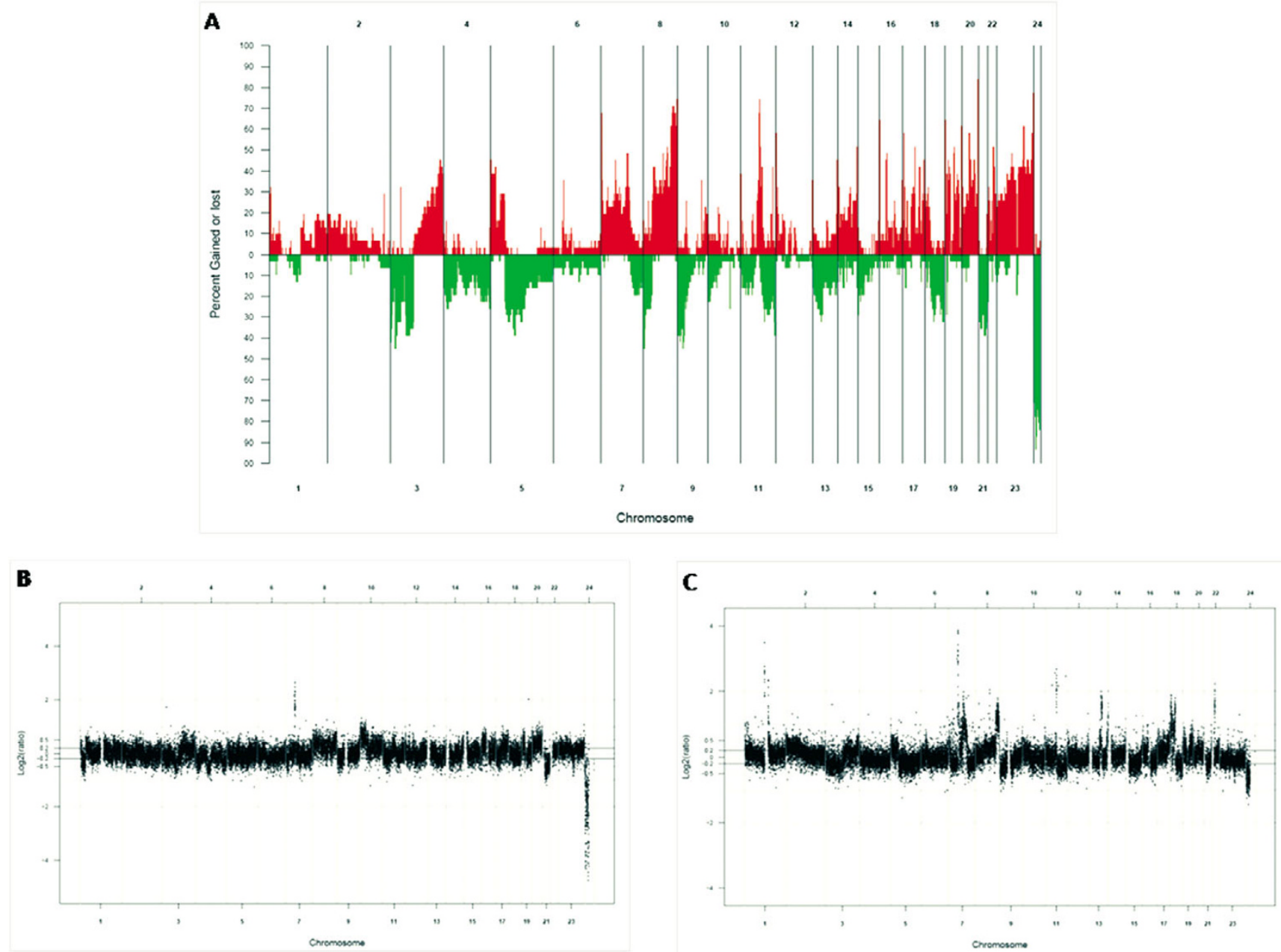

Figure I

A) Genome-wide frequency plot of DNA copy number gains (red) and losses (green) for all 30 ESCC tumors. B) Genome-wide copy number profile for a Stage I tumor (ESCC 33). Characteristic alterations for a Stage I tumors are gains on 6p, I2p, and 17p and losses 2Iq. C) Genome-wide copy number profile for a Stage IV tumor (ESCC 5I). Characteristic for Stage IV tumors are gains on I2p, 19q and $20 q$ and frequent losses on $3 p, 5 q$ and $9 p$. 
tumors showed a higher number of changes, with the most common gains affecting 12p13.33 (100\%), 5p15.33 (85\%), 20q13.33 (85\%) and 11q13.3 (77\%). Overall, copy number losses were more common in stage II tumors and the most frequent losses were shared by different tumor stages without a significant difference in frequency (see Additional file 3 and 4).

Smaller (pT1) tumors had the lowest number of copy number changes (mean 12\% of the clones affected), whereas pT2-T4 tumors showed alterations of 27\%, 16\%, and $18 \%$ of the clones. When gains/losses were correlated to presence of lymph node metastases, 838 clones that mapped to 21 genomic regions were identified (see Additional file 5). Copy number gain in 7p22.3 was significantly $(P=0.01)$ associated with lymph node metastases, and correctly predicted nodal metastases in $63 \%$ of the patients, as represented by an area under ROC curve of 0.73. Changes in 19 regions, corresponding to 1074 clones, correlated to metastasis at diagnosis (see Additional file 6) with copy number gain of 8q21.3 being significantly associated with the presence of metastasis $(\mathrm{P}=$ 0.03 ). Gain of $8 q 21.3$ could classify $60 \%$ of the patients with distant metastasis with $40 \%$ sensitivity and $70 \%$ specificity.

Univariate analysis verified that stage and tumor size were associated with prognosis; stage HR 1.6, $P=0.04$ and pT HR $1.8, P=0.05$. When copy number gains and losses were correlated to prognosis, Cox proportional hazards analysis identified 1284 clones, with a p-value <0.05, mapping to 30 regions (see Additional file 7). When gains and losses were separately considered, 7 regions remained significantly associated to prognosis in univariate analysis. When these regions were entered with stage into multivariate analysis, gain of $1 \mathrm{p} 36.32$ and gain of 19p13.3 independently predicted poor prognosis (Table 2 and Figure 2).

\section{Discussion}

Array-based genomic profiling of ESCC confirms the genetic complexity suggested by earlier studies that have applied other means of genetic profiing, e.g. cytogenetics, conventional $\mathrm{CGH}$, and $\mathrm{LOH}$ analysis. We found copy number gains and losses affecting median 19\% of the genome, identified multiple high-level amplications, and demonstrated an association between copy number alterations and stage, differentiation and prognosis, suggesting clinical applicability of genomic profiling in ESCC.

The $11 \mathrm{q} 13$ region is central in ESCC development and alterations herein were identified in 20/31 tumors. CCND1 is a likely target, but several other candidate genes, e.g. FGF4, FGF3, CTTN and SHANK2, showed highlevel amplification. This amplicon harboured MYEOV,
Table 2: Regions correlated to prognosis in univariate and multivariate Cox analysis. Table listing the regions significantly correlated to prognosis in univariate and multivariate analysis. Columns give the type of aberration, cytoband, hazard ratio (HR), P-value and confidence interval (Cl).

\begin{tabular}{|c|c|c|c|c|}
\hline \multicolumn{5}{|c|}{ A - Univariate Cox analysis } \\
\hline Aberration & Cytoband & HR & $P$ & Cl \\
\hline Gain & $19 p \mid 3.3$ & 5.0 & 0.005 & $1.6-15.5$ \\
\hline Gain & $3 q \mid 1.2$ & 6.4 & 0.012 & $1.5-26.8$ \\
\hline Loss & $10 p \mid 1.23$ & 10.3 & 0.013 & $1.6-65.4$ \\
\hline Loss & $9 q 34.3$ & 27.5 & 0.019 & $1.7-439$ \\
\hline Gain & $3 q 22.3$ & 3.7 & 0.025 & $1.1-11.6$ \\
\hline Loss & $10 q 11.21$ & 6.2 & 0.026 & $1.2-31.1$ \\
\hline Gain & Ip36.32 & 3.4 & 0.030 & $1.1-10.6$ \\
\hline \multicolumn{5}{|c|}{ B - Multivariate Cox analysis } \\
\hline Aberration & Cytoband & HR & $\mathbf{P}$ & $\mathbf{C l}$ \\
\hline Gain & Ip36.32 & 19.6 & 0.005 & $2.5-153.9$ \\
\hline Gain & $19 p \mid 3.3$ & 7.0 & 0.011 & $1.5-31.9$ \\
\hline Stage & & 2.0 & 0.077 & $0.9-4.4$ \\
\hline
\end{tabular}

which has previously been associated with ESCC and described to be co-amplified with CCND1 [22]. The RB pathway is frequently targeted in ESCC carcinogenesis [23-25] and its activation seems to be dependent mainly on CCND1 amplification. In our sample set no significant correlations were observed between the gains/losses observed in the members of the RB pathway (CCND1, CCNE1, E2F3 and CDKN2A). Gain of 14q32.3, which includes the $A K T 1$ oncogene, was identified in half of the samples. The PTEN-PIK3CA-AKT signalling cascade is frequently deregulated in several types of cancers and expression of PIK3CA has been strongly associated with elevated AKT activity. An increased copy number of PIK3CA is primarily detected in tumors with retained PTEN expression [26], and indeed, none of the 11 tumors with PIK3CA gain showed loss of the PTEN locus at 10q23.3, whereas 7 tumors showed PTEN loss without change at PIK3CA locus. The pairwise analysis showed a negative $(P=0.005)$ correlation of both copy number gains. Expression data from array-based oligonucleotide arrays were available from 8 samples (unpublished data) and verified overexpression of PIK3CA in 7 of these tumors, which further supports PIK3CA and PTEN acting as mutually exclusive tumorigenic events [27]. Gain of 7p11.2 was identified in half of the tumors and included high-level amplifications in 4 tumors. The most likely target gene herein, EGFR, is overexpressed in a multitude of malignancies and including ESCC [7,28-30]. Immunostaining for EGFR was highly positive $(3+)$ in 12 out of 14 tumors with copy number gain of EGFR, thus suggesting, as previously reported $[28,31,32]$, that copy number gain leads to high 

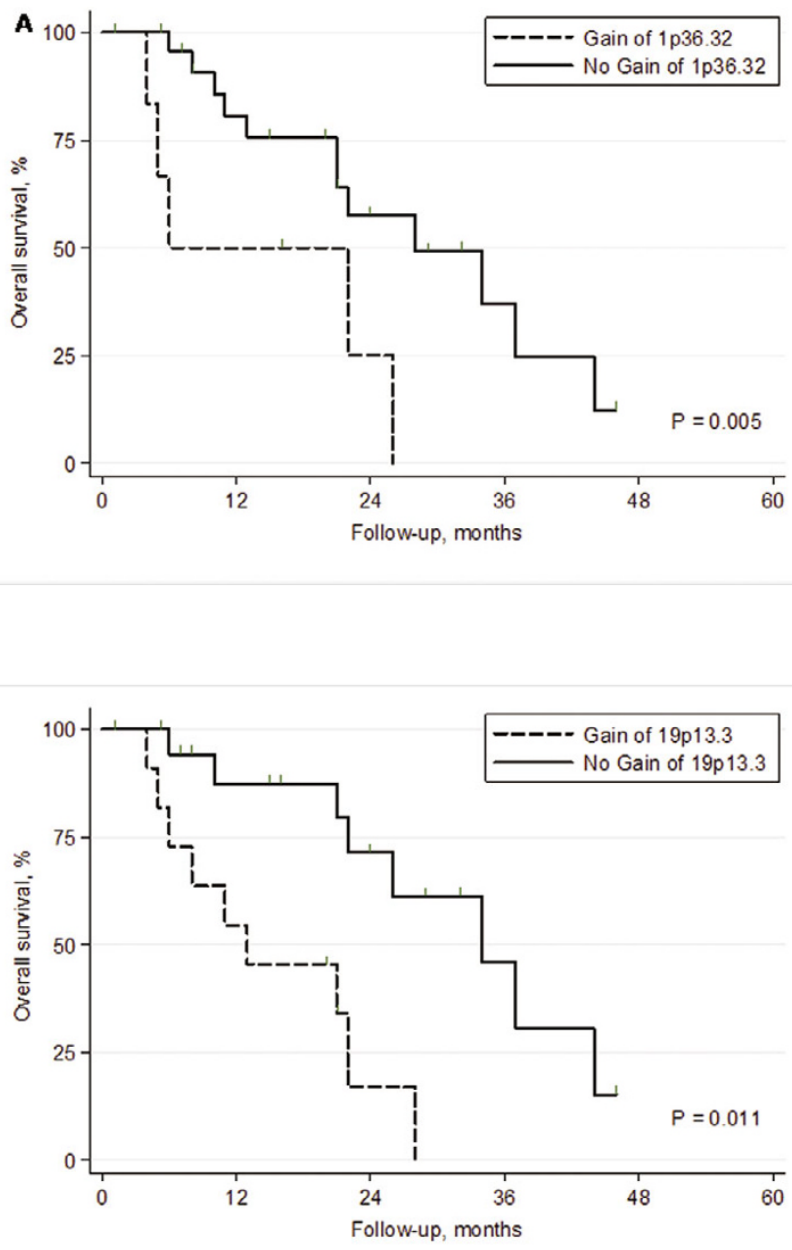

Figure 2

Kaplan-Meier survival plots of the two prognostic regions in multivariate analysis. A) Highly significant difference in survival between patients without gain and with gain of IP36.32 $(P=0.005)$. B) Difference in survival between patients without gain and with gain of $19 \mathrm{p} \mid 3.3(P=0.0 \mathrm{I})$.

protein expression in a significant fraction of tumors (86\% in our sample set).

In our cohort, loss of PTEN was observed in $23 \%$ of the samples and was significantly correlated $(P=0.04)$ to EGFR gain, which may be relevant for resistance to EGFR inhibitors, since PTEN loss correlates with treatment resistency. Furthermore, gain of 17q12, harbouring ERBB2, was observed in 9 tumors and 6 of these showed concomitant gain of 7p11.2 (EGFR), which suggests that co-overexpression of ERBB2 and EGFR may apply also to ESCC [33]. High level amplification of ERBB2 correlated to overexpression (data not shown). Copy number gain of 5 p15 was among the most frequent changes and the min- imal region of overlap harbour some 20 identified genes, among which the telomerase regulator TERT, which has previously been shown to be overexpressed in ESCC and has been associated with prognosis in other tumor types [12,34-36]. Gains of 7p22.3, 8q22.3-qter and 20q11.21 were also frequently found and include the target genes MAD1L1 involved in TERT transcription, LRP12 and WISP1 linked to cell survival and p53-mediated apoptosis and TPX2 known to activate Aurora-A kinase [37-41]. High-level amplifications affected 33 loci, among which recurrent high-level amplification peaks were detected at 7p11 (EGFR), 11q22 (cIAP1, MMP3 and PDGF), 11q13 (that harbours e.g. CCND1, FGF4, FGF3, CTTN and SHANK2), and 10q21 with unknown targets.

The most frequent recurrent copy number losses affected $3 p, 5 p, 8 p, 9 p$, and $11 q$, which is consistent with other studies and these loci also contain several tumor suppressors linked to ESCC $[2,3,8,42]$. Losses affecting the 9p21p24 region, which contains $C D K N 2 A$ and $C D K N 2 B$, were identified in 13/30 tumors. CDKN2A deletions have been associated with an invasive and metastatic phenotype and a homozygous CDKN2A deletion was identified in one sample [43-45]. Frequent losses were also observed at 3p26-p14 which harbours THRB, RARB, TOP2B and FHIT. Pairwise correlations between frequently observed gains and losses identified 5 regions that were significantly more often affected by concurrent aberrations. Four of these were located on the same chromosome, whereas loss of 3p24 and 5q12 occurred at an increased incidence. These regions contain targets such as TOP $2 B, R A R B$, and TGFBR2 on $3 \mathrm{p}$ and PIK3R1 and RAD17 on $5 \mathrm{q}$, and the association identified may indicate cross-talk between genes in these regions.

\section{Conclusion}

The accumulation of genetic changes is central in ESCC development and progression. Our study is the first to apply high-resolution aCGH to clinical prognostication in ESCC. Studies that have applied traditional CGH have suggested a prognostic independent role for genes located on $8 \mathrm{q}, 11 \mathrm{q}, 12 \mathrm{p}, 14 \mathrm{q}$, and $20 \mathrm{q}[2,16,46]$, and a recent study using a $4 \mathrm{k}$ BAC array platform (with $1 \mathrm{Mb}$ resolution) identified 4 clones, mapping to 3q29, 4q21.21, $8 q 24$ and 8q24.3, linked to survival [47]. The high-resolution data here presented demonstrates extensive genetic complexity already in early stage tumors, supports the involvement of several key genes in ESCC, links gain of 7 p22.3 to presence of nodal metastases and demonstrates that gains of $1 \mathrm{p} 36.32$ and 19p13.3 provide independent prognostic information ( $\mathrm{HR}=19.6$ and 7.0 respectively). The different prognostic regions identified may be related to the inherent genetic complexity of ESCC, to differences in materials (e.g. study populations from different geographic areas with disparities in dietary and environmen- 
tal exposures) and use of different genetic profiling technologies [48,49]. Nevertheless, these results hold promise for the application as genetic classifiers and refined prognostic markers. Moreover, the recognition of recurrent rearrangements in central signaling pathways provides a basis for the development of selected and individualized targeted therapeutics in ESCC.

\section{Competing interests}

The author(s) declare that they have no competing interests.

\section{Authors' contributions}

AC designed the study, performed experiments, analyzed the data and drafted the manuscript. AI contributed to the design of the study, performed experiments and helped to draft the manuscript. AK carried out experiments and analyzed data. JJ provided cancer samples and clinical data. GJ helped the data analysis. POB performed and supervised statistical analysis. DF provided cancer samples. $\mathrm{BH}$ performed pathological analysis of tumor samples. $\mathrm{MN}$ conceived, designed and coordinated the study, and helped to draft the manuscript. All authors read and approved the final manuscript.

\section{Additional material}

\section{Additional file 1}

Clinicopathologic variables of tumors and survival of patients of the sample set. Table listing the clinicopathologic variables of tumors and survival of patients of the sample set analyzed in this study.

Click here for file

[http://www.biomedcentral.com/content/supplementary/14712407-8-98-S1.xls]

\section{Additional file 2}

Number of gains and losses by differentiation. Boxplot of the number of gained and lost clones according to tumor differentiation.

Click here for file

[http://www.biomedcentral.com/content/supplementary/14712407-8-98-S2.tiff]

\section{Additional file 3}

Number of gains and losses by tumor stage. Boxplot of the number of gained and lost clones according to tumor stage.

Click here for file

[http://www.biomedcentral.com/content/supplementary/14712407-8-98-S3.tiff]

\section{Additional file 4}

Copy number alterations, listed in decrescent prevalence order, in relation to tumor stage. Table listing the most frequent copy number alterations, sorted in decreasing order, in relation to tumor stage. Columns give the cytoband, start reporter, end reporter, size (Mbp), frequency of the change and candidate genes in the region.

Click here for file

[http://www.biomedcentral.com/content/supplementary/14712407-8-98-S4.xls]

\section{Additional file 5}

Chi2 test significant regions associated with positive lymph nodes $(P<$ 0.05). Table listing the regions of aberrations that showed a significant statistical $(\mathrm{P}<0.05)$ association with positive lymph nodes. Given are cytoband, start reporter, end reporter, size $(\mathrm{Mbp})$ and the frequency across patients with positive lymph nodes and patients with negative lymph nodes. P-values were computed using Chi2 test.

Click here for file

[http://www.biomedcentral.com/content/supplementary/14712407-8-98-S5.xls]

\section{Additional file 6}

Chi2 test significant regions associated with metastasis at diagnosis $(P<$ 0.05). Table listing the regions of aberrations that showed a significant statistical $(\mathrm{P}<0.05)$ association with metastasis at diagnosis. Given are cytoband, start reporter, end reporter, size $(\mathrm{Mbp})$ and the frequency across patients with metastasis at diagnosis and patients without metastasis at diagnosis. P-values were computed using Chi2 test.

Click here for file

[http://www.biomedcentral.com/content/supplementary/14712407-8-98-S6.xls]

\section{Additional file 7}

Regions correlated to prognosis identified by Cox analysis. Table listing the regions of aberrations significantly correlated $(\mathrm{P}<0.05)$ to prognosis in univariate Cox analysis. Cytoband, start reporter, end reporter and size $(\mathrm{Mbp})$ of the aberrant region are given.

Click here for file

[http://www.biomedcentral.com/content/supplementary/14712407-8-98-S7.xls]

\section{Acknowledgements}

The study was financially supported by grants from the Knut and Alice Wallenberg Foundation via the Swegene program, the Swedish Cancer Society, the Swedish Research Council, the Nilsson Cancer Research Fund, the Kamprad Research Fund, the Region Skåne Research Funds and the American Cancer Society (GJ). AC was supported by a grant from the Portuguese Institute of Oncology (Lisbon) and from the Portuguese League Against Cancer (South Region Centre).

\section{References}

I. Metzger R, Schneider PM, Warnecke-Eberz U, Brabender J, Holscher $\mathrm{AH}$ : Molecular biology of esophageal cancer. Onkologie 2004, 27(2):200-206.

2. Yen CC, Chen YJ, Chen JT, Hsia JY, Chen PM, Liu JH, Fan FS, Chiou TJ, Wang WS, Lin $\mathrm{CH}$ : Comparative genomic hybridization of esophageal squamous cell carcinoma: correlations between chromosomal aberrations and disease progression/prognosis. Cancer 200I, 92(II):2769-2777.

3. Pack SD, Karkera JD, Zhuang Z, Pak ED, Balan KV, Hwu P, Park WS, Pham T, Ault DO, Glaser M, et al.: Molecular cytogenetic fingerprinting of esophageal squamous cell carcinoma by comparative genomic hybridization reveals a consistent pattern of chromosomal alterations. Genes, chromosomes \& cancer 1999, 25(2): $160-168$.

4. Du Plessis L, Dietzsch E, Van Gele M, Van Roy N, Van Helden P, Parker MI, Mugwanya DK, De Groot M, Marx MP, Kotze MJ, et al:: Mapping of novel regions of DNA gain and loss by comparative genomic hybridization in esophageal carcinoma in the Black and Colored populations of South Africa. Cancer research 1999, 59(8): 1877-1883.

5. Tada K, Oka M, Hayashi H, Tangoku A, Oga A, Sasaki K: Cytogenetic analysis of esophageal squamous cell carcinoma cell 
lines by comparative genomic hybridization: relationship of cytogenetic aberrations to in vitro cell growth. Cancer Genet Cytogenet 2000, II 7(2): 108-II 2.

6. Shinomiya $T$, Mori T, Ariyama $Y$, Sakabe T, Fukuda $Y$, Murakami $Y$, Nakamura $Y$, Inazawa J: Comparative genomic hybridization of squamous cell carcinoma of the esophagus: the possible involvement of the DPI gene in the 13q34 amplicon. Genes, chromosomes \& cancer 1999, 24(4):337-344.

7. Ishizuka T, Tanabe C, Sakamoto H, Aoyagi K, Maekawa M, Matsukura N, Tokunaga A, Tajiri T, Yoshida T, Terada M, et al.: Gene amplification profiling of esophageal squamous cell carcinomas by DNA array CGH. Biochem Biophys Res Commun 2002, 296(I): $152-155$

8. Arai H, Ueno T, Tangoku A, Yoshino S, Abe T, Kawauchi S, Oga A, Furuya T, Oka M, Sasaki K: Detection of amplified oncogenes by genome DNA microarrays in human primary esophageal squamous cell carcinoma: comparison with conventional comparative genomic hybridization analysis. Cancer Genet Cytogenet 2003, I 46(I):16-21.

9. Jiang W, Kahn SM, Tomita N, Zhang YJ, Lu SH, Weinstein IB: Amplification and expression of the human cyclin $D$ gene in esophageal cancer. Cancer research 1992, 52(10):2980-2983.

10. Shinozaki H, Ozawa S, Ando N, Tsuruta H, Terada M, Ueda M, Kitajima M: Cyclin DI amplification as a new predictive classification for squamous cell carcinoma of the esophagus, adding gene information. Clin Cancer Res 1996, 2(7): I I55-I I6I.

II. Hollstein MC, Smits AM, Galiana C, Yamasaki H, Bos JL, Mandard A, Partensky C, Montesano R: Amplification of epidermal growth factor receptor gene but no evidence of ras mutations in primary human esophageal cancers. Cancer research 1988, 48(I8):5II9-5I23.

12. Lu SH, Hsieh LL, Luo FC, Weinstein IB: Amplification of the EGF receptor and c-myc genes in human esophageal cancers. International journal of cancer 1988, 42(4):502-505.

13. Shiomi H, Sugihara H, Kamitani S, Tokugawa T, Tsubosa $Y$, Okada K, Tamura H, Tani T, Kodama M, Hattori T: Cytogenetic heterogeneity and progression of esophageal squamous cell carcinoma. Cancer Genet Cytogenet 2003, I47(I):50-6I.

14. Hu N, Roth MJ, Polymeropolous M, Tang ZZ, Emmert-Buck MR, Wang QH, Goldstein AM, Feng SS, Dawsey SM, Ding T, et al.: Identification of novel regions of allelic loss from a genomewide scan of esophageal squamous-cell carcinoma in a high-risk Chinese population. Genes, chromosomes \& cancer 2000, 27(3):217-228.

15. Huang Y, Boynton RF, Blount PL, Silverstein RJ, Yin J, Tong Y, McDaniel TK, Newkirk C, Resau JH, Sridhara R, et al.: Loss of heterozygosity involves multiple tumor suppressor genes in human esophageal cancers. Cancer research 1992, 52(23):6525-6530.

16. Kwong D, Lam A, Guan X, Law S, Tai A, Wong J, Sham J: Chromosomal aberrations in esophageal squamous cell carcinoma among Chinese: gain of $12 \mathrm{p}$ predicts poor prognosis after surgery. Hum Pathol 2004, 35(3):309-316.

17. Jonsson G, Staaf J, Olsson E, Heidenblad M, Vallon-Christersson J, Osoegawa K, de Jong P, Oredsson S, Ringner M, Hoglund M, et al.: High-resolution genomic profiles of breast cancer cell lines assessed by tiling BAC array comparative genomic hybridization. Genes, chromosomes \& cancer 2007, 46(6):543-558.

18. The BioArray Software Environment (BASE) website [http:/ /base2.thep.lu.se/onk/]

19. Saal LH, Troein C, Vallon-Christersson J, Gruvberger S, Borg A, Peterson C: BioArray Software Environment (BASE): a platform for comprehensive management and analysis of microarray data. Genome Biol 2002, 3(8):SOFTWARE0003.

20. Yang YH, Dudoit S, Luu P, Lin DM, Peng V, Ngai J, Speed TP: Normalization for cDNA microarray data: a robust composite method addressing single and multiple slide systematic variation. Nucleic Acids Res 2002, 30(4): 15.

21. Autio R, Hautaniemi S, Kauraniemi P, Yli-Harja O, Astola J, Wolf M, Kallioniemi A: CGH-Plotter: MATLAB toolbox for CGH-data analysis. Bioinformatics 2003, I9(13): I7|4-I7|5.

22. Janssen JW, Imoto I, Inoue J, Shimada Y, Ueda M, Imamura M, Bartram CR, Inazawa J: MYEOV, a gene at IIqI3, is coamplified with CCNDI, but epigenetically inactivated in a subset of esophageal squamous cell carcinomas. J Hum Genet 2002, 47(9):460-464.
23. Kawakubo H, Ozawa S, Ando N, Kitagawa Y, Mukai M, Ueda M, Kitajima M: Alterations of p53, cyclin DI and pRB expression in the carcinogenesis of esophageal squamous cell carcinoma. Oncology reports 2005, 14(6): |453-1459.

24. Nakajima $Y$, Miyake S, Tanaka K, Ogiya K, Toukairin Y, Kawada K, Nishikage T, Nagai K, Kawano T: The expressions of p2 I and pRB may be good indicators for the sensitivity of esophageal squamous cell cancers to CPT-I I: Cell proliferation activity correlates with the effect of CPT-II. Cancer science 2004, 95(5):464-468.

25. Mathew R, Arora S, Khanna R, Mathur M, Shukla NK, Ralhan R: Alterations in $\mathrm{p} 53$ and $\mathrm{pRb}$ pathways and their prognostic significance in oesophageal cancer. Eur J Cancer 2002, 38(6):832-84I.

26. Altomare DA, Testa JR: Perturbations of the AKT signaling pathway in human cancer. Oncogene 2005, 24(50):7455-7464.

27. Pedrero JM, Carracedo DG, Pinto CM, Zapatero AH, Rodrigo JP, Nieto CS, Gonzalez MV: Frequent genetic and biochemical alterations of the PI 3-K/AKT/PTEN pathway in head and neck squamous cell carcinoma. International journal of cancer 2005, I I 4(2):242-248

28. Hanawa M, Suzuki S, Dobashi Y, Yamane T, Kono K, Enomoto N, Ooi A: EGFR protein overexpression and gene amplification in squamous cell carcinomas of the esophagus. International journal of cancer 2006, I I 8(5): I I73-1 I80.

29. Sunpaweravong P, Sunpaweravong S, Puttawibul P, Mitarnun W, Zeng C, Baron AE, Franklin W, Said S, Varella-Garcia M: Epidermal growth factor receptor and cyclin DI are independently amplified and overexpressed in esophageal squamous cell carcinoma. J Cancer Res Clin Oncol 2005, I 3 I(2): I I I-I I9.

30. Gibault L, Metges JP, Conan-Charlet V, Lozac'h P, Robaszkiewicz M, Bessaguet C, Lagarde N, Volant A: Diffuse EGFR staining is associated with reduced overall survival in locally advanced oesophageal squamous cell cancer. $\mathrm{Br}\rfloor$ Cancer 2005, 93(I): $107-115$.

3I. Janmaat ML, Gallegos-Ruiz MI, Rodriguez JA, Meijer GA, Vervenne WL, Richel DJ, Van Groeningen C, Giaccone G: Predictive factors for outcome in a phase II study of gefitinib in second-line treatment of advanced esophageal cancer patients. J Clin Oncol 2006, 24(10):1612-1619.

32. Personeni $\mathrm{N}$ : Epidermal growth factor receptor gene copy number in esophageal cancer and outcome prediction to gefitinib: does intratumoral heterogeneity matter? J Clin Oncol 2006, 24(34):5465. author reply 5466-5467

33. DiGiovanna MP, Stern DF, Edgerton SM, Whalen SG, Moore D 2nd Thor AD: Relationship of epidermal growth factor receptor expression to ErbB-2 signaling activity and prognosis in breast cancer patients. J Clin Oncol 2005, 23(6): I I52-II60.

34. Hsu CP, Lee LW, Shai SE, Chen CY: Clinical significance of telomerase and its associate genes expression in the maintenance of telomere length in squamous cell carcinoma of the esophagus. World J Gastroenterol 2005, I I(44):694I-6947.

35. Barclay JY, Morris A, Nwokolo CU: Telomerase, hTERT and splice variants in Barrett's oesophagus and oesophageal adenocarcinoma. European journal of gastroenterology \& hepatology 2005, I 7(2):22I-227.

36. Zhang H, Jin Y, Chen X, Jin C, Law S, Tsao SW, Kwong YL: Cytogenetic aberrations in immortalization of esophageal epithelial cells. Cancer Genet Cytogenet 2006, I 65(I):25-35.

37. Ohta Y, Hamada Y, Saitoh N, Katsuoka K: Effect of the transcriptional repressor MadI on proliferation of human melanoma cells. Exp Dermatol 2002, I I(5):439-447.

38. Garnis C, Coe BP, Zhang L, Rosin MP, Lam WL: Overexpression of LRP I 2, a gene contained within an 8q22 amplicon identified by high-resolution array CGH analysis of oral squamous cell carcinomas. Oncogene 2004, 23( 14):2582-2586.

39. Xu L, Corcoran RB, Welsh JW, Pennica D, Levine AJ: WISP-I is a Wnt-I- and beta-catenin-responsive oncogene. Genes Dev 2000, I 4(5):585-595.

40. Wang XX, Liu R, Jin SQ, Fan FY, Zhan QM: Overexpression of Aurora-A kinase promotes tumor cell proliferation and inhibits apoptosis in esophageal squamous cell carcinoma cell line. Cell Res 2006, 16(4):356-366.

4I. Tong T, Zhong Y, Kong J, Dong L, Song Y, Fu M, Liu Z, Wang M, Guo $L$, Lu $S$, et al:: Overexpression of Aurora-A contributes to 
malignant development of human esophageal squamous cell carcinoma. Clin Cancer Res 2004, I 0(21):7304-7310.

42. Noguchi T, Takeno S, Kimura Y, Uchida Y, Daa T, Yokoyama S, Gabbert HE, Mueller W: FHIT expression and hypermethylation in esophageal squamous cell carcinoma. Int J Mol Med 2003, I I(4):44|-447.

43. Takeuchi H, Ozawa S, Ando N, Kitagawa Y, Mukai M, Ueda M, Kitajima M: Further evidence that altered pl6/CDKN2 gene expression is associated with lymph node metastasis in squamous cell carcinoma of the esophagus. Oncology reports 200I, 8(3):627-632.

44. Tokugawa T, Sugihara H, Tani T, Hattori T: Modes of silencing of pl 6 in development of esophageal squamous cell carcinoma. Cancer research 2002, 62(17):4938-4944.

45. Takeuchi H, Ozawa S, Ando N, Shih CH, Koyanagi K, Ueda M, Kitajima M: Altered pI6/MTSI/CDKN2 and cyclin DI/PRAD-I gene expression is associated with the prognosis of squamous cell carcinoma of the esophagus. Clin Cancer Res 1997, 3( I 2 Pt I):2229-2236.

46. Ueno $T$, Tangoku A, Yoshino S, Abe T, Hayashi $H$, Toshimitsu $H$, Hashimoto K, Satoh T, Oga A, Furuya T, et al.: Prediction of nodal metastasis by comparative genomic hybridization in biopsy specimens from patients with superficial esophageal squamous cell carcinoma. Clin Cancer Res 2003, 9( I4):5 I37-5 I4I.

47. Hirasaki S, Noguchi T, Mimori K, Onuki J, Morita K, Inoue H, Sugihara $\mathrm{K}$, Mori M, Hirano T: BAC clones related to prognosis in patients with esophageal squamous carcinoma: an array comparative genomic hybridization study. The oncologist 2007, I 2(4):406-4I 7 .

48. Wang Z, Tang L, Sun G, Tang Y, Xie Y, Wang S, Hu X, Gao W, Cox SB, Wang JS: Etiological study of esophageal squamous cell carcinoma in an endemic region: a population-based case control study in Huaian, China. BMC cancer 2006, 6:287.

49. Wang JM, Xu B, Rao JY, Shen HB, Xue HC, Jiang QW: Diet habits, alcohol drinking, tobacco smoking, green tea drinking, and the risk of esophageal squamous cell carcinoma in the Chinese population. European journal of gastroenterology \& hepatology 2007, 19(2): $17 \mid-176$.

\section{Pre-publication history}

The pre-publication history for this paper can be accessed here:

http://www.biomedcentral.com/1471-2407/8/98/prepub http.//www.biomedcentral.com/1471-2407/8/98 